\title{
SMS Texting and Its Potential Impacts on Students' Written Communication Skills
}

\author{
Solomon Ali Dansieh \\ Department of General and Liberal Studies, Wa Polytechnic \\ P. O. Box 553, Wa, Upper West Region, Ghana \\ Tel: 233-24-471-7406 E-mail: sdansieh@yahoo.com
}

Received: March 31, $2011 \quad$ Accepted: April 28, $2011 \quad$ doi:10.5539/ijel.v1n2p222

\begin{abstract}
This article seeks to examine the transformative impact of SMS text messaging on student written communication skills. Using the survey method, the article examines how pervasive the use of SMS texting is among polytechnic students; its possible effects on students' writing skills; and, what lecturers and students themselves think about the phenomenon. Based on responses from survey participants, the article argues that even though mobile phones are handy ICTs for harnessing and disseminating information, they could have their dark side too: the SMS text messaging function could heighten the tendency among students to adopt non-standard uses and contracted forms of English words in their classwork, examinations and research reports especially in an academic environment where English is the L2 of most students.
\end{abstract}

Keywords: Simple Message System (SMS), Text messaging, Student written communication skills, Bane

\section{Introduction}

As more and more students worldwide acquire and use mobile phones, so are they immersing themselves in text messaging. Such is the situation that some teachers, parents and students themselves are expressing concerns that student writing skills stand the risk of being sacrificed on the altar of text messaging. The phenomenon has brought in its wake three main schools of thought. While some educators and students think that text messaging is one of the banes of mobile telephony because of its possible negative impact on writing skills of students; others contend that it rather enhances their written communication skills, and therefore is a blessing. A third group thinks that the argument is neither here nor there - text messaging has neither positive nor negative impact on student writing. The first school of thought bases its argument on the fact that for the sake of brevity, concision, and economy, the simple message system (SMS) of text messaging throws the essential mechanics of writing such as grammar, syntax, punctuation and capitalization to the wind. The other school of thought, spearheaded by the renowned linguist, David Crystal, thinks otherwise: text messaging does not really pose a threat as many fear it can. The more students write, the more they improve upon their writing skills. Therefore, its increased use rather enhances the literacy of users, especially the youth in stead of harming it (Crystal, 2008). The debate is carried to another level by the third group who doubt whether texting really has any effect (positive or negative) on English grammar at all. These views will be expanded later under the literature review section. I would like to posit that text messaging in itself is not bad. It is its misuse, especially, the unbridled use of abbreviations and non-standard expressions and spellings and their possible negative impact on student writing skills that must be watched. Before weighing the pros and cons of text messaging and its potential effects on student writing skills, the next section discusses what prompted this study.

\subsection{The problem}

Concern has been expressed by faculty and staff about the poor communication skills of Wa Polytechnic (Note 1) students. Following such complaints, the Academic Board commissioned a committee in 2006 to investigate the causes of poor communication skills among students of the Polytechnic and to recommend ways of arresting the situation. The Committee came out with the following findings: English was every student's second language (L2). Students have been studying the language for an appreciable period, with the mean year being $183 / 4$. A total of $99 \%$ of respondents admitted they liked English language, even as a subject, while $73 \%$ believed that the poor communication skills exhibited by students was ascribable to poor foundation, dating back to early years of their study of the language. The report further observed that while about $51 \%$ of students found grammar very difficult, $36 \%$ struggled with lexis and structure. It concluded that, with $98 \%$ of students interviewed admitting that they needed help to improve upon their general communication skills; the problem was deep-rooted (Wa Polytechnic, 2006: 5\&6). One may ask, four years down the line, has the situation improved or worsened? With records from the Academic Affairs Department of the Wa Polytechnic indicating that the average grade in English language by applicants to various Higher National Diploma programmes between the 2006/2007 and 
2010/2011 academic years has been E - ordinary pass (Wa Polytechnic, 2010), it will be interesting to find out whether text message language has come to ameliorate or aggravate the situation. At a recent seminar for Vice Rectors and Industrial Liaison Officers of Polytechnics in Ghana held at the Takoradi Polytechnic (from $1^{\text {st }}$ to $3^{\text {rd }}$ March, 2010), it was reported under "Critical observations" that a greater number of polytechnic students who did their attachment with GHACEM Limited, Takoradi, had difficulty in communicating effectively in the English language. They were thus unable to clearly convey messages during interviews or normal working schedules. "The students either failed to construct good sentences or fumbled in oral expressions and so failed to succeed generally in the global workplace", the report further stated (Takoradi Polytechnic, 2010: $5 \&$ 6). The two reports aptly summarise the state of affairs regarding student communication skills, especially writing. Text messaging involves writing; but, does SMS language and writing really help students in their writing skills? What does the literature say about the phenomenon generally? What empirical evidence is there to depict the situation at the Wa Polytechnic? What are the some of the common abbreviations observable in students' work? What do the lecturers think about their possible impact on students' writing?

\subsection{Objectives of study}

The study aims at,

- contributing to the debate on text messaging and to find out how it affects students' writing skills in a country like Ghana where English is not the L1 of students;

- determining how pervasive the use of text messaging is among polytechnic students;

- sourcing the opinions of faculty on the phenomenon;

- using empirical evidence obtained from a survey to prove the negative impact or otherwise of SMS text messaging on student written communication skills; and

- to make recommendations as to how its negative impact, if any, can be mitigated.

To achieve these objectives I propose to go about the study using the survey approach; but first, a look at what the literature says about the phenomenon elsewhere.

\section{Literature review}

Considering the relatively short history of mobile telephony in general and SMS text messaging in particular (December 1992 to 2010), it is rather amazing the level of interest it has generated among researchers and authors around the world. Not many books have been written on the subject yet. In 2007, Finnish author Hannu Luntiala published the first ever book written solely in text message language, about a business executive traveling throughout Europe and India (Crystal, 2008). The following year, David Crystal, a renowned Linguistics Professor came out with his book entitled Txtng: The Gr8 Db8. This could be said to be the most comprehensive literary work so far on the SMS text messaging. Various researches on the impact of SMS texting have also been carried out and findings published in journals, newspapers, and on the internet. These articles, mostly online, address the positive and negative impacts of text messaging on various aspects of social life, including the academic work of students. While one school of thought argues that the service is a curse, because it impacts negatively on student communication skills, particularly writing skills; the other, led by David Crystal, contends that texting is not harmful to student literacy; rather it enhances it (Crystal 2008). In his book, Txtng: The Gr8 Db8, (a logogram which stands for Texting: The Great Debate), Crystal refutes the popular view that SMS language and its profuse use of abbreviations and slang can impact negatively on student language and literacy. His claim was based on six main points; that: (1) in a typical text message, less than $10 \%$ of the words are abbreviated; (2) abbreviating has been in use for decades, and thus is not a new language; (3) children and adults alike use text language, the latter being more likely to do so; (4) students do not habitually use abbreviations in their homework and examinations; (5) before people can text, they must first know how to spell. Texting can therefore not be a cause of bad spelling; (6) since texting provides people with the opportunity of engaging with the language through reading and writing, it improves people's literacy. A third school of thought contends that it has no effect on grammar. They argue that SMS texting should be considered as another language, and since learning a new language does not affect students' ability to use English grammar, it would be wrong to conclude that text messaging can affect their grammar. They point out that slang words have no effect on English grammar, and that even though each generation has its own jargon, English grammar has not been changed. All students need to do, they claim, is learn the basics in English class and they will be able to distinguish between "slang, texting lingo and correct English" (Russell, 2010).

In spite of the apparently huge volumes of work on the subject, the literature is silent on the phenomenon as it pertains to a regional technical tertiary institution in an African country where English is not the mother tongue (L1) of the students. This paper seeks to fill in this gap by finding out whether some of the claims made in the literature hold true for students of a young institution like the Wa Polytechnic, where the grades which majority of applicants obtained in English Language could best be described as "gentleman passes" in student parlance i.e. the barest pass one can get in a core subject, or borderline grades. In an academic environment where one out 
of every three students came in with a combination of results obtained from two or more sittings of the West African Senior Secondary School Certificate Examination (WASSSCE), Senior Secondary School Certificate Examination (SSSCE) or the newly introduced bridging programme - Access Course (a bridging course), one wonders whether text messaging can really be the blessing that some claim it can be to students' written communication skills.

There is no doubt that text messaging has some impacts on the way people talk and write - some negative; others positive depending on the content and context. An article posted under "Wikinews" reported that in November 2006, the New Zealand Qualifications Authority gave its approval to the move that secondary school students be allowed to use mobile phone text language in the end of year examination papers. This could probably be ascribed to the pervasiveness of SMS text lingo among the students. However, following the wide publication of reports dating back to 2002 on the use of text language in school assignment, some sections of the public became concerned about the decline in the quality of written communication. It was also reported that teachers and professors had started having difficulty in keeping the trend in check (Wikipedia, 2010). What then is SMS text messaging? And, what is so special about it that it has generated such a great debate?

\subsection{SMS text messaging}

Text messaging is the practice whereby users of mobile and portable devices exchange brief written messages via cellular networks. While the act of sending a text message is termed "texting", the sender is called a "texter." It is used in place of voice calls in circumstances where it may be impossible or inexpedient. Generally, texting is considered more economical. Some people simply text because it is relatively cheaper compared to placing a phone call to another mobile phone. Originally, it referred to messages sent using the Short Message Service (SMS); but as is characteristic of most technologies, the service has undergone transformations to cover messages that contain image, video, and sound. It has also evolved from person-to-person messaging to include interaction with automated systems and is available on a wide range of networks. There is a bit of controversy as to who actually invented the SMS. In some quarters credit is given to Neil Papworth, a 22-year-old test engineer for Sema Group (now Airwide Solutions), who is said to have been the first to invent the service in 1992, using a personal computer to text "Merry Christmas" through the Vodafone network to the phone of one Richard Jarvis (Wikipedia, 2010). In some other quarters, credit is given to Matti Makkonen, a pioneer in Finnish mobile communications (Dogbevi, 2008). Today, text messaging is considered the most widely used mobile data service. Its use around the globe can simply be described as pervasive. It is on record that by the end of 2007 , half of the world's population (3.3 billion) was mobile phone subscribers. Out of this, 2.4 billion people, constituting $74 \%$ of all mobile phone users worldwide, were active users of the SMS (Wikipedia, 2010). With an average of 27 texts sent per day by subscriber, the Philippines is considered the world's largest average user of the SMS by mobile phone subscribers. Scandinavia, particularly Finland, Norway and Sweden had over $85 \%$ of their population using SMS over the same period. By the end of 2008, the European average and North American SMS-active-user rate had risen to about $80 \%$ and $60 \%$ respectively. The International Telecommunications Union in a report released in 2009 rated Africa as "the region with the highest mobile growth rate" at the close of 2008 (ITU, 2009). Although Africa's ICT penetration levels in general lagged behind the rest of the world, it defied all predictions in the area of mobile cellular telephony, with subscriptions rising from just $5 \%$ in 2003 to over $30 \%$ by the end of 2008. As far as SMS usage in Ghana is concerned, it is hard to come by statistics. Dogbevi (2008) reports that available statistics dates back to 2000 when it was estimated that SMS sent from Ghana grew from an initial 22,000 to over 130,000. The figure could be much higher now, given that Ghana's current mobile telephony density stands at about 7.6 million subscribers.

\subsection{Forms of texting}

Text messaging mostly involves the use of pictograms and logograms. Words are either shortened through the use of symbols to represent the word, or using symbols whose names sound like a syllable of the word. A text may consist of words or an alphanumeric combination. For example, texting "to date" could be rendered as $2 \mathrm{~d} 8$; "for you", as $4 \mathrm{U}$; and "before" as b4. To text "to whom it may concern" for instance, one could simply write twimc. "Love you with all my heart" could also be texted as "luwamh" (BBC-Focus on Africa, 2004:25). Several syllables of a word can also be substituted using numeral sequences. An example is the French a12c4 " $a$ un de ces quartres" meaning "see you around" (cited in Wikipedia, 2010:12). It is also possible to use numbers alone to communicate whole passages. This is particularly so in character-based languages like Chinese and Japanese. For instance, "8807701314520" in Chinese is literally translatable as "Hug hug you, kiss kiss you, whole life I love you" (Ibid). The SMS technology allows up to 160 characters in length for each short message composed with Latin alphabets, and 70 characters in length for those composed with non-Latin alphabets like Arabic and Chinese.

\subsection{Some uses of SMS text messaging}

Text messaging has caught on so well with mobile phone users, partly because of its ubiquity. Today, many are those who consider their mobile phones "first as text messaging devices, and secondly as voice calling devices" 
(Wikipedia, 2010). Wherever there is mobile phone reception, text messaging is possible. When United States President Obama was delivering his speech in Accra during his visit to Ghana in 2009, the U.S. Department of State reached citizens all over the world using SMS. Through SMS, live highlights of the speech were received by African and international/non-U.S. citizens around the world in French and English (Butcher, 2009). Power and Power (2004) also observed that even deaf people are able to communicate with each other better through SMS.

In addition to interpersonal communication through texting, ordering products and services, texting votes (i.e. SMS voting), and participating in contests or polls have also become common features of the service. For instance, MTN subscribers in Ghana who are customers of Société Générale-Social Security Bank (SG-SSB) can receive statements of their balances through "Sikatext" - literally "moneytext", and even top up credit by simply texting their request to a given code. Another recent service that uses text messaging is MTN's "mobile money transfer." Of late, one thing that many a Ghanaian mobile phone user is gradually getting sick of is the unbridled use of texts by service providers to notify subscribers about various promotions. All sorts of raffles are now being drawn through texting. The National Lotteries Authority (NLA) has recently also adopted the service as a means by which people could stake the weekly lotto. In Uganda, farmers are able to access the real price of their crops with mobile phones via SMS. This way, they avoid being cheated by unscrupulous middlemen (Ross, 2004). In Kenya, SMS money transfers called M-Pesa which was pioneered by SAFARICOM has become so popular that between April 2007 and April 2010, the number of users soured from 52, 000 to 9.7 million according to company statistics (Agence France Presse, 2010).

The Global Messaging Survey conducted by Nokia in 2002 revealed that text messaging has addictive tendencies. This finding was confirmed by a study undertaken at the Catholic University of Leuven in Belgium in 2004. Following these, another study at the University of Queensland in Australia found that "text messaging is the most addictive digital service on mobile or internet," adding that "the text reception habit introduces a need to remain connected" (Wikipedia, 2010: 3). By this facility, a sense of connectedness of users is assured even in circumstances where voice calls may not be practicable or acceptable. It also provides users with the convenience of responding to messages when they deem fit.

\subsection{Some attested impact on language}

The impact of text messaging on language has generated a great deal of debate. While researchers like Rosen et al (2009) are of the view that regular use of the service can impact negatively on the everyday language of "texters", linguistic experts like Crystal (2008) refute this stance. In an unscientific poll conducted by Edutopia.org, out of 1028 respondents, $50 \%$ were of the view that texting was harming students' writing and grammar. $20 \%$ thought that text messaging could have some effect on students' writing; but did not consider it a major problem; while $27 \%$ felt it did not have any negative influence (Russell, 2010). One respondent was cited to have remarked "...my students' spelling is atrocious. Texting does not and has not helped" (Ibid). Whereas some teachers were of the view that abbreviations used in text messaging was negatively affecting written English, reporting that papers had been written without due regard to proper punctuation, good grammar, and standard abbreviations, other educators felt that the more you got students to write, the better (O'Connor, 2005). This group contends that texting even provides an opportunity for teachers to teach about how language has evolved from Shakespearean English to Internet English. They argue that text messaging is not just writing anything, but that before students send out text messages, they do some editing in order to format the messages into a limited but precise number of words. A third school of thought contends that text messaging has no effect on English grammar. In their view, text messaging could be considered as another language. Since learning a new language or slang words does not necessarily affect a student's ability to use English grammar, text messaging as another language cannot either. They argue that each generation has its own jargon, yet English grammar has not changed. Therefore, all that students need to do is learn the basics in English class what the distinctions between slang, texting lingo and Standard English are (Russell, 2010).

\section{Methods and data collection}

As a descriptive case study, both quantitative and qualitative approaches to the collection and analysis of numerical and narrative data were adopted, and the strands integrated using triangulation (Yin, 1994). This was done to ensure reliability and validity of findings as either approach has been noted to have some shortcomings (Lynch, 1988). Two sets of survey questionnaires - one for students and the other for lecturers - were developed to gather primary data for quantitative analysis using version 16.0 of the Statistical Package for Social Sciences (SPSS) software. Samples of the questionnaires can be found in appendixes 1 and 2. A total of 430 questionnaires, (i.e. 400 to students, and 30 to lecturers) were randomly administered. With a total student population of 1,300 and academic staff strength of 68 , these sample sizes were considered reasonable enough to enable the researcher do a fair assessment of the problem at the Wa Polytechnic. The questionnaires included both open and closed-ended items. There were some multiple-choice questions as well; all aimed at establishing mobile phone ownership, usage, opinions and experiences with texting problems among students of the Wa Polytechnic. The study also drew some material from secondary data from magazines, reports, and online journal articles. As a means of ensuring reliability of findings and confirming what students and faculty say about the 
possible negative effects of the phenomenon, marked examination scripts in Secretarial English and Communication Skills were also sampled for study. Findings from the survey are presented under Section 4.

\subsection{Limitations}

The study was not without limitations though. Some of the limitations that were encountered bordered on the timing of the questionnaire - the second semester examination season of the 2009/2010 academic year. While it was considered the best time for student participation, it turned out that it was not the most convenient of times for faculty, as most of them were invigilating. Soon afterwards, deadlines were also given for submission of exam results. This contributed to the delays in the return of responses from faculty. The study did not also consider issues like the social and psychological effects of text messaging on students. This is an area that future research could study. The limited number of books on the subject also compelled the researcher to draw most of his references from on-line sources.

\section{Results}

The study provides varied information retrieved from the 430 questionnaires and anecdotal information from the polytechnic. It contains results and discussions employing graphs and tables for purposes of pictorial illustrations. These can be found in Appendices A to C.

\subsection{Analysis and discussions responses}

\subsubsection{Socio-demographic characteristics of respondents}

The ages of student respondents ranged from 20 to 50 years with the $20-30$ age bracket constituting the highest $334(83.5 \%)$ user group followed by the $31-40$ age group with $62(15.5 \%)$ while students who fell within the 41 - 50 year bracket were only $4(1 \%)$. Table 1 , which portrays the age-sex compositions of respondents is attached Appendix A. The variety in the age groups of student respondents' participation in the use of mobile phones confirms Kamran's observation that "people of all ages have benefited from the mobile phone consumptions in modern societies" (Kamran, 2010:26). Table 1 again shows the sex composition of respondents and recorded $32.5 \%$ female with $67.5 \%$ male respondents; while the phone usage component recorded $93 \%$ and $7 \%$ for users and non-phone users respectively. This finding portrays gender non-exclusion in the use of mobile phones.

\subsubsection{Mobile phone usage amongst students}

The $93 \%$ phone usage rate among student respondents probably demonstrates a high frequency of phone usage among Wa Polytechnic students. However, the low percentage $32.5 \%$ ) for the female respondents does not necessarily imply that male students outnumbered their female colleagues in mobile phones ownership and usage. This probably indicates the general situation in northern Ghana, where female enrolment in most tertiary educational institutions is generally low. The random sampling approach adopted in data collection did not also necessitate assigning quotas to the two genders

It was also observed that about $90.7 \%$ of respondents have been using mobile phones for more than a year; while only $9 \%$ used it for less than a year. This high duration in usage probably reinforces the high frequency of mobile phone usage amongst students in the Wa Polytechnic.

Figure 1 in Appendix B also depicts the multi-functional purposes of the mobile phone and how students employ this in their daily activities. The survey further revealed that about $71 \%$ of the student respondents used mobile phones for voice calls while $13.2 \%, 8.9 \%, 5.4 \%, 1.0 \%$ and $0.5 \%$ were recorded for text messaging, browsing the internet, photo/video/music, banking, and for receiving TV signals respectively. This probably showed varied and multiple usages of the mobile phone facility among student respondents and that aside voice calls, the incident of text messaging was common among student respondents.

Generally, about $51.6 \%$ of the student respondents' text severally a day; while $38.7 \%$ and $9.7 \%$ sent text messages either once daily or occasionally respectively. This implies that text messaging was conventional and high among student respondents. Also the $84.4 \%$ intimation of using abbreviated form of words in texting is suggestive of the possible common use of abbreviations by students. The frequency and form that text messages took are displayed in Figure 2 in Appendix C.

On account of the effect of SMS text messaging on student course work, about $84.4 \%$ intimated having employed the abbreviated forms. This is probably where the use of phone, especially text massaging, influenced the writing skills and ability of students. It was further revealed that the aspects of writing being affected by the text massaging syndrome included sentences, spelling, and both which recorded $25.5 \%, 41.4 \%$ and $33.1 \%$ respectively. This affirms the fact that text massaging had a major impact on students' performance and quality of work. The negative effect of text messaging was more problematic when about $65.9 \%$ intimated they developed their own ways of abbreviations; while $34.1 \%$ copied those developed by friends. This became pronounced when it permeated students' academic activities with recordings of about $24 \%$ admissions.

\subsubsection{Common text abbreviations observed in students' work by lecturers}

The incidence of text abbreviation in academic work amongst students was particularly exposed when $58.3 \%$ of responses from lecturers showed varied forms of abbreviation used in scripts they marked. Some of the 
commonest abbreviations as cited by lecturers included 'É', 'ê', 'e' for the, 'c' see, 'u' you, 'b/4 for before', '2moro' for tomorrow, '\&' for and, 'etc', 'eg' for example; 'Eng' English/Engineering, ' $\rightarrow$ ', ' $\uparrow$ ', ' $\downarrow$ ', 'ur' for your, 'pls' for please, '2day' for today, 'lke' for like, 'de' for thee, 'nub' for number, 'shd' for should, 'luv' for love, among others. It was observed that some of these abbreviations were so messy that not only was it difficult to identify the letters; but they also made making meaning out of entire constructions very problematic. These revelations are testimonies to the creeping negative effects of the use of mobile phone text abbreviations on students' academic work, progression and general development. It is also indicative of the prevalence of the negative effects of SMS text messaging in our tertiary institutions generally. This was confirmed by the $82.4 \%$, and $15.8 \%$ records for 'harmful' and 'may be harmful' responses respectively from lecturers and $0 \%$ records for both the 'not harmful' and 'none' options.

\subsubsection{Effects of abbreviated writings on academic work/performance}

The negative effects of student abbreviated writings in academic work according to lecturer respondents generally, were bad (52\%), posed reading problems (33\%) and delayed script marking process $(19 \%)$. This negates the positive impact of text messaging as generalized by David Crystal, and also Russell's argument of the nil effect of phone abbreviations texting but brings to light the position of the schools of thought that argues that phone abbreviation texting could negatively impact on grammar, not excluding students works as demonstrated by this work.

Students rating by lecturers with $57.5 \%, 23.1 \%, 9.1 \%, 8.3 \%$ and $0 \%$ responses for average, poor, good, very good and excellent respectively showed the low level of students' performance and the effect of mimicking phone text abbreviation on students' academic work. The effect of text massaging could only worsen the performance rating of students and therefore requires intervention to stem the situation.

The usage of text message lingo in classwork and examinations was confirmed when sample marked examination scripts in Secretarial English and Communication Skills were sampled for study. These two subject areas were chosen because they contained answers to composition questions which required students to write more than 250 words under stipulated time frames, and thus had a high likelihood of exposing their weaknesses in spelling, sentence construction and grammar. From the sampled papers, it was observed that there were mistakes relating to the mechanics of English language, which actually, were directly related to SMS text message lingo. Beyond the text messaging effect on students, the general effects on the use of the mobile were particularly highlighted when $75 \%$ of lecturer respondents intimated the incidence of disruption of attention during lectures. The creeping negative effects of text message abbreviations on student scripts, and the generalized nuisance of phone usage disturbance during lectures prompted the suggestions of measures such as sanctions/marks deductions $(27.5 \%)$, encouraging proper language use $(15.3 \%)$, giving feedback from scripts (29.2\%), counseling/orientation (15.8\%) and $4.2 \%$ for conducting dictations for students.

\subsection{Policy effect and suggestions on phone usage in school}

The phone use policy developed by the Wa Polytechnic Academic Board makes the possession and use of phones during examination an offense. Mobile phones found on students during examinations are therefore impounded and culprits made to pay GH $\$ 5.00$ after the paper before the release of the phone. The ban on mobile phone use in exam halls is often stated in the examinations regulations. However, about $50 \%$ of lecturer respondents feigned ignorance about the existence of this policy. This is probably due to some lecturers' non-response to calls for discussions on examinations regulations prior to the commencement of examinations. This problem could be stemmed if these regulations were discussed at the departmental levels. Also about 50\% of lecturers' intimation of having instituted measures such as switching phones off during lecturers, sending culprits out of lectures on offense among others was reflective of lecturers' commitment towards remedying the canker.

\section{Conclusion and suggestions}

From the results obtained through the survey, it is evident that mobile phone use among Wa Polytechnic students is very high (94\%). Using the device specifically for text messaging is also common $(13.4 \%)$ and has the potential to rise when hostel facilities and student accommodation are available on the campus. With such empirical evidence from an environment where all respondents in the target group had English as their L2, we would like to posit that generalising the positive impact of SMS text messaging on student literacy as Crystal and others claim could be misleading. The 11 languages (English, French, Spanish, Italian, German, Swedish, Finnish, Welsh, Dutch, Chinese and Portuguese) that Crystal's study considered are known for their conservatism when it comes to adopting other foreign languages; so one would expect that the bulk of his respondents must have been native speakers of those languages. Also given the findings of the Communications Skills Committee (Wa Polytechnic, 2006) and complaints by faculty and employers that an appreciable number of students struggle with grammar, lexis and structure, text messaging which encourages abbreviating and non-conformity with grammatical rules, could worsen students' written communication skills rather than improve them. The students themselves and their teachers confirmed this when $83 \%$ of them and $70 \%$ of 
lecturers in the survey admitted that SMS language can harm their writing skills. Statistics from the Academic Affairs Department of the Wa Polytechnic Registry also indicates that most students did not obtain strong enough grades in the English language at the West African Senior Secondary School Examinations (WASSSCE).

In view of the attested addictive effects of text messaging (Nokia, 2002), caution must be exercised in encouraging students in its use. If not checked, students are likely to get so used to it that they may no longer realise the need for Standard English constructions even in writings that are supposed to be formal, a phenomenon O'Connor (2005) describes as "saturation." With findings obtained from the survey conducted among Wa Polytechnic staff and students, it is evident that SMS text messaging could pose a threat to student writing skills and therefore must not be entertained by faculty in student assignments and examinations. The written communication skills of students are already poor. Various reports have proven this. Even among current (Note 2) applicants for enrolment into the institution for the 2010/2011 academic year, majority of them (83\%) obtained grade E in English at the West African Secondary School Certificate Examinations (WASSCE). Thus, the argument that SMS text messaging is a blessing because it helps improve students' written communication skills may hold water elsewhere; but not at the Wa Polytechnic. The phenomenon may seem not to be that grave now; but that is most probably because Wa Polytechnic students have not yet reached the point of 'saturation' in their use of SMS text message lingo, and are therefore a bit conscious of distinguishing between formal and informal writing contexts. Evidence obtained from sample marked scripts indicates that the harmful effects of text messaging on student writing skills is yet to become a major threat at the Wa Polytechnic. Be that as it may, it is important to eschew complacency and rather adopt conscious and pragmatic measures now so as to prevent the phenomenon from further worsening students' writing skills. All efforts must therefore be made to help students write good English whether on phone on paper. The practice by some faculty of only marking content and not expression and mechanical accuracy, must cease immediately.

\section{References}

Agence France Presse. (2010). Text message cash transfers booming in South, East Africa. [Online] Available: http://news.malaysia.msn.com (May 24, 2010).

Butcher, D. (2009). Obama's Ghana speech highlights delivered live via SMS. Mobile marketer, 15 July, 2009.

Crystal, D. (2008). Txtng: The Gr8 Db8. Oxford: Oxford University Press.

Dogbevi, E. K. (2008). How SMS technology is changing lives in Ghana. Ghana Business News, 6 December, 2008. [Online] Available: http://www.ghanabusinessnews.com (March 6, 2010).

International Telecommunications Union. (2009). Information Society Statistical Profiles 2009: Africa. Johannesburg: ITU.

Kamran, S. (2010). Mobile Phone: Calling and texting patterns of college students in Pakistan. International Journal of Business and Management, Vol. 5, No. 4, April.

Luntiala, H. (2007). Viimeiset viestit (Last Messages). Helsinki: Tammi.

Lynch, B. (1988). Toward a context-adaptive model for the evaluation of language teaching programmes. Los Angeles: University of California. Dissertation Abstracts International 48: 2264A

Nokia. (2002). Are you ready for multimedia messaging service: An evolutionary approach to implementing MMS. [Online] Available: www.nokia.com (April 20, 2010).

O'Connor, A. (2005). Instant Messaging: Friend or foe of student writing? New Horizons for Learning, March 2005. [Online] Available: http://www.newhorizons.org/strategies/literacy/oconnor.htm (May 28, 2010).

Power, M. R., and Power, D. (2004). Everyone here speaks txt: Deaf people using SMS in Australia and the rest of the world. Journal of Deaf Studies and Deaf Education, Vol. 9, p.333-343. doi:10.1093/deafed/enh042, http://dx.doi.org/10.1093/deafed/enh042

Ross, W. (2004). "Inside Information” BBC, Focus on Africa January-March 2004. London: BBC.

Russell, L. (2010). The effects text messaging on English grammar. [Online] Available: http://www.ehow.com/list_5828172_effects-text-messaging-english-rammar.html (April 20, 2010).

Takoradi Polytechnic. (2010). Rapporteur-General's report. Report on a three-day seminar for Vice Rectors and Industrial Liaison Officers of the ten Polytechnics in Ghana, Monday $1^{\text {st }}$ March to Wednesday $3^{\text {rd }}$ March 2010.

Wa Polytechnic. (2006). An investigation into the causes of poor performance of students in communication skills. A report submitted by the Communication Skills Committee to the Academic Board. May, 2006.

Wikipedia. (2010). Text messaging. [Online] Available: http://en.wikipedia.org/wiki/Text_messaging $(28 / 5 / 2010)$.

Yin, R. (1994). Case study research: Design and methods. Beverly Hills: Sage Publications. 


\section{Notes}

Note 1. The Wa Polytechnic was established in 1999 by the Government of Ghana as the last of ten regional polytechnics in Ghana. Located in rural Upper West Region of Ghana, majority of its students come from deprived schools, usually with weak grades in the English Language.

Note 2. Source: Academic Affairs Unit of the Wa Polytechnic Registry. Available data as of 07/06/10.

Appendix A: Age-Sex Distribution and Phone Use of Respondents

Table 1. Age, sex and phone use distribution of student respondents

\begin{tabular}{|l|c|c|}
\hline \multicolumn{2}{|c|}{ AGE DISTRIBUTION OF STUDENT RESPONDENTS } \\
\hline Variables & $\begin{array}{c}\text { Frequency } \\
\mathbf{N}=\mathbf{( 4 0 0 )}\end{array}$ & $\begin{array}{c}\text { Percentage } \\
\text { (\%) }\end{array}$ \\
\hline Age Range of Students & 334 & 83.5 \\
$20-30$ & 62 & 15.5 \\
$31-40$ & 4 & 1.0 \\
$41-50$ & 130 & 32.5 \\
\hline Sex Composition & 270 & 67.5 \\
Female & 372 & 93 \\
Male & 28 & 7 \\
\hline Phone usage amongst students & $\mathbf{N = 3 7 2}$ & \\
Phone users & 338 & 90.7 \\
Non-phone users & 34 & 9.3 \\
\hline Duration in phone use & & \\
Above one year & & \\
Below one year & & \\
\hline
\end{tabular}

Appendix B: Common Phone Uses by Students

\section{Text Messaging Form and Frequency}

neveral text daily abbreviated text usage

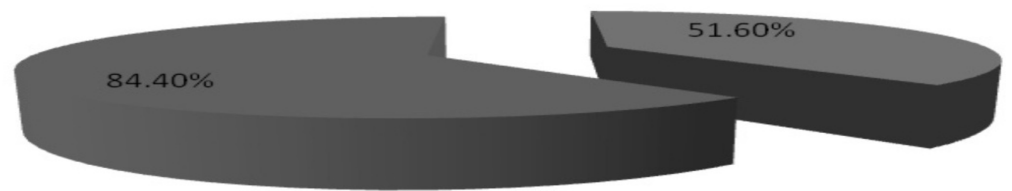

Appendix C: Form and Frequency of Text Messages by Students

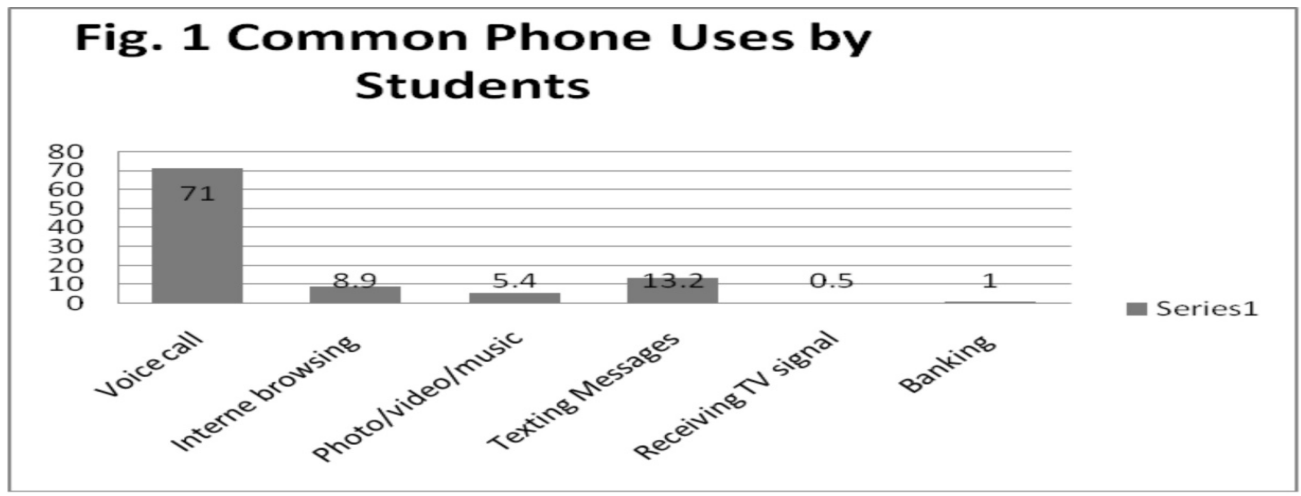

